Article

\title{
Self-Assembled Monolayers of Molybdenum Sulfide Clusters on Au Electrode as Hydrogen Evolution Catalyst for Solar Water Splitting
}

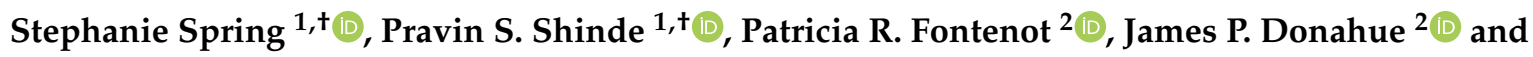 \\ Shanlin Pan $1, *$ D \\ 1 Department of Chemistry and Biochemistry, University of Alabama, Tuscaloosa, AL 35487, USA; \\ stephaniespring97@yahoo.com (S.S.); psshinde@ua.edu (P.S.S.) \\ 2 Department of Chemistry, Tulane University, New Orleans, LA 70118, USA; pfonten@tulane.edu (P.R.F.); \\ donahue@tulane.edu (J.P.D.) \\ * Correspondence: span1@ua.edu; Tel.: +1-205-348-6381 \\ + Authors with equal contribution; Stephanie Spring is The Research Experiences for Undergraduates (REU) \\ student of summer 2018 at The University of Alabama.
}

Received: 1 May 2019; Accepted: 21 June 2019; Published: 25 June 2019

\begin{abstract}
Hydrogen evolution reaction (HER) activities of self-assembled monolayers (SAMs) of $\left[\mathrm{Mo}_{3} \mathrm{~S}_{7}\left(\mathrm{~S}_{2} \mathrm{CNMe}_{2}\right)_{3}\right]$ and several other $\mathrm{MoS}_{x}$ molecular clusters are presented on planer Au electrode. Our study suggests that such Mo-S clusters are unstable under HER reaction conditions of a strongly acidic electrolyte. The $\left[\mathrm{Mo}_{3} \mathrm{~S}_{7}\left(\mathrm{~S}_{2} \mathrm{CNEt}_{2}\right)_{3}\right] \mathrm{I}$ monolayer prepared from DMF showed greater stability among all the studied precursors. The X-ray photoelectron spectroscopy (XPS) analysis on a monolayer of $\left[\mathrm{Mo}_{3} \mathrm{~S}_{7}\left(\mathrm{~S}_{2} \mathrm{CNMe}\right)_{3}\right] \mathrm{I}$ in THF assembled on Au/ITO suggested sulfur-rich composition with S:Mo ratio of 2.278. The Mo-S monolayer clusters resulting from $\left[\mathrm{Mo}_{3} \mathrm{~S}_{7}\left(\mathrm{~S}_{2} \mathrm{CNMe}_{2}\right)_{3}\right] \mathrm{I}$ in THF showed a Tafel slope of $75.74 \mathrm{mV} \mathrm{dec}^{-1}$ and required a lower overpotential of $410 \mathrm{mV}$ to reach a high HER catalytic current density of $100 \mathrm{~mA} \mathrm{~cm}^{-2}$ compared to the other studied precursors. Surface coverage of the Mo-S clusters on the $\mathrm{Au}$ surface was confirmed by cyclic voltammetry $(\mathrm{CV})$ curves from $\mathrm{K}_{3} \mathrm{Fe}(\mathrm{CN})_{6}$ and anodization of $\mathrm{Au}$ surface. Further, the rotating ring-disk electrode (RRDE) measurements were performed for the monolayer of $\left[\mathrm{Mo}_{3} \mathrm{~S}_{7}\left(\mathrm{~S}_{2} \mathrm{CNMe}_{2}\right)_{3}\right] \mathrm{I}$ prepared in THF to study its reaction kinetics. The HER catalytic activity of such monolayer Mo-S clusters can further be improved by controlling the sulfur vacancy.
\end{abstract}

Keywords: hydrogen evolution reaction; self-assembled monolayer; rotating ring disc electrode

\section{Introduction}

Due to the adverse environmental effects of fossil fuels and their rapid decrease in availability, there is a growing demand for developing new clean and renewable energy resources. Solar power could be a viable solution to this problem, as it is a readily available and abundant source of renewable energy [1]. One of the popular methods among various emerging power conversion technologies is photoelectrochemical (PEC) water splitting that utilizes solar energy alongside electrochemistry to split water to produce hydrogen-based fuels in solar-to-fuel devices [2]. PEC water splitting involves the following necessary steps: (1) absorption at the photocatalyst such that the photon energy absorbed is more than the band gap energy of the photocatalyst; (2) generation of photo-excited electron-hole pairs; (3) separation of these charges across the surface of the photocatalyst without recombination; and (4) reduction and oxidation of water by the photogenerated electrons and holes to produce $\mathrm{H}_{2}$ and $\mathrm{O}_{2}$ [3]. The first three steps are primarily dependent on the structural and electronic properties of the photocatalyst, whereas the co-catalyst drives the last step. PEC water splitting can be challenging due to the need of thermodynamic potential of $-1.23 \mathrm{~V}$ vs. RHE at least for the reaction to occur as 
well as the requirements for an efficient photocatalyst. Some of these requirements include a suitable band gap that lies within 1.6-2.5 eV, band edge position that lies between the redox potentials of $\mathrm{H}_{2} \mathrm{O}$, a charge transfer rate fast enough to prevent photocorrosion and shifting of the band edges. The photocatalyst must also be stable, nontoxic, and abundantly available [3]. Most popular and widely employed photocatalysts in solar-to-fuel devices include semiconductors such as $\mathrm{TiO}_{2}$ and $\mathrm{ZnO}$. However, these semiconductors have a higher band gap, which limits the amount of actual sunlight they can utilize and convert to energy. $\mathrm{TiO}_{2}$, for example, has a band gap of 3.0-3.2 eV, which requires UV light to operate. Solar light consists of $5 \%$ UV, $43 \%$ visible, and $52 \%$ infrared light [4]. Therefore, developing a new photocatalyst that exhibits higher activity when exposed to visible light is preferable. However, it is difficult to have such photocatalysts. The semiconductors that are visible-light active are either less catalytic or prone to stability issues. On the other hand, some materials/organic compounds are highly catalytic but do not contribute much under visible-light. Noble metal nanoparticles (NPs) have the potential to address this issue; for instance, Au NPs show high optical absorption in the visible region $(500-600 \mathrm{~nm})[4,5]$. The approach is to synergistically improve the water splitting performance by combining the visible-light-absorbing and highly catalytic materials. Platinum is the best-known electrocatalyst for the hydrogen evolution reaction (HER). However, its scarcity and enormous cost make it a poor choice for use in solar-to-hydrogen devices. Therefore, developing low-cost and Earth-abundant catalysts with a performance comparable to that of Pt-group metals is crucial [6]. Some examples of Earth-abundant HER electrocatalyst include transition metal-based sulfides (e.g., $\mathrm{MoS}_{2}$ [7], $\mathrm{CoS}_{2}$ [8], and $\mathrm{WS}_{2}$ [9]), selenides (e.g., $\mathrm{MoSe}_{2}$ [10], $\mathrm{NiSe}_{2}$ [11], and $\mathrm{CoSe}_{2}$ [12]), phosphides (e.g., $\mathrm{Ni}_{2} \mathrm{P}$ [13] and FeP [14]), carbides (e.g., Ni/C [15] and MoC [16]), and molecular organic catalysts (e.g., cobalt and nickel diimine-dioxime complexes [17] and ligand-centered homogeneous electrocatalysts [18]). Recently, monolayers of metal chalcogenide-based molecular catalysts are gaining interest due to their structural tunability and low-cost production $[19,20]$.

Molybdenum sulfide $\left(\mathrm{MoS}_{2}\right)$ is one such promising candidate, which has the potential to replace precious metal catalysts for sustainable development towards hydrogen generation. $\mathrm{MoS}_{2}$ is a renowned HER catalyst, known for its excellent ability to absorb hydrogen and activate it for the reduction of organo-sulfur and organo-nitrogen molecules in the hydrotreating of crude petroleum. Several forms of molybdenum sulfide such as amorphous $\operatorname{MoS}_{x}$ [21,22], crystalline $\operatorname{MoS}_{2}[23,24]$, sulfur-rich [25,26] or sulfur-deficient [27,28] $\mathrm{MoS}_{2}$, and metal-promoted $\mathrm{MoS}_{2}$ [29] have been synthesized on conducting substrates via simple solution-based chemical techniques that includes drop-casting, dip-coating, hydrothermal, and electrodeposition. Such HER electrocatalysts achieved a Tafel slope in the range of $39-95 \mathrm{mV} \mathrm{dec}^{-1}$ and overpotential in the range of $150-300 \mathrm{mV}$ at $10 \mathrm{~mA} \mathrm{~cm}^{-2}$ [30].

Various speculations about the origin of the catalytic ability of $\mathrm{MoS}_{2}$ have been reported in the literature ranging from edge site configuration to sulfur vacancy, to the assembled structure of $\mathrm{MoS}_{2}[4,31,32]$. Regarding sulfur vacancy, it was observed that a vacancy density of $7-10 \%$ could drastically shift the onset potential to more positive potentials [32]. A variety of studies have been conducted in trying to maximize the catalytic ability of $\mathrm{MoS}_{2}$ by changing the concentration, the method of $\mathrm{MoS}_{2}$ deposition, the number of layers deposited, and the semiconductor material [4,24]. A few of these studies have chosen to study as-grown $\mathrm{MoS}_{2}$, which requires several days to synthesize the as-grown $\mathrm{MoS}_{2}$ [31,33]. Our team recently demonstrated a simple method of coating catalytic $\mathrm{MoS}_{2}$ layer onto $\mathrm{Cu}_{2} \mathrm{O}$ photocathode to enhance its stability and hydrogen evolution reaction under sunlight illumination [24]. $\mathrm{MoS}_{2}$ coating on top of $\mathrm{Cu}_{2} \mathrm{O}$ has been achieved by spin coating appropriate amount of $\left[\mathrm{Mo}_{3} \mathrm{~S}_{7}\left(\mathrm{~S}_{2} \mathrm{CNEt}_{2}\right)_{3}\right] \mathrm{I}$ precursor solution combined with a thermal annealing process to obtain the optimal stoichiometry. $\mathrm{MoS}_{2}$ thin films synthesized using this method exhibited good prospects as both a protective layer and an electrocatalyst for hydrogen evolution reactions (HER) due to excellent stability and high electrocatalytic activity, as shown in Figure 1. Through this work, we demonstrated a sustained proton reduction performance from $\mathrm{Cu}_{2} \mathrm{O}$ photocathode using $\sim 40 \mathrm{~nm}$ thick coating of $\mathrm{MoS}_{2}$, which was prepared by spin-coating three layers of $2.5 \mathrm{mM} \mathrm{MoS}_{2}$ precursor solution on the $\mathrm{Cu}_{2} \mathrm{O}$ surface. Although the enhanced catalytic performance for HER from two-dimensional (2D) $\mathrm{MoS}_{2}$ 
has been widely reported in the literature, the role of monolayer $\mathrm{MoS}_{2}$ is still not well understood. Few reports on monolayer $\mathrm{MoS}_{2}$ have been concentrated on investigating their electrochemical and kinetic properties using CV, XPS, and RRDE techniques, and Tafel slope measurements to understand the HER mechanisms.
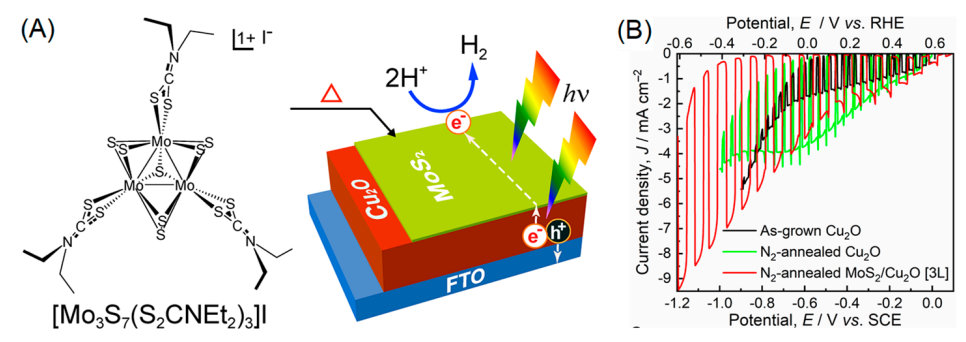

Figure 1. (A) Schematic showing the formation of a proton reduction catalytic $\mathrm{MoS}_{2}$ layer on top of a p-type $\mathrm{Cu}_{2} \mathrm{O}$ via spin coating $\left[\mathrm{Mo}_{3} \mathrm{~S}_{7}\left(\mathrm{~S}_{2} \mathrm{CNEt}_{2}\right)_{3}\right] \mathrm{I}$ and thermal annealing. $\mathrm{Cu}_{2} \mathrm{O}$ was electrodeposited on fluorine-doped tin oxide (FTO) substrate; and (B) photocurrent responses of as-grown $\mathrm{Cu}_{2} \mathrm{O}$, $\mathrm{N}_{2}$-annealed $\mathrm{Cu}_{2} \mathrm{O}$, and $\mathrm{N}_{2}$-annealed $\mathrm{MoS}_{2}$-modified $\mathrm{Cu}_{2} \mathrm{O}$ photocathodes under intermittent light illumination in $0.5 \mathrm{M} \mathrm{Na}_{2} \mathrm{SO}_{4}(\mathrm{pH} \sim 6.7)$; light: simulated 1 sun $\left(100 \mathrm{~mW} \mathrm{~cm}^{-2}\right)$. Reproduced with permission from [24], published by Royal Society of Chemistry, 2018.

Here, we propose using $\mathrm{Au}$ instead of $\mathrm{Cu}_{2} \mathrm{O}$ due to the $\mathrm{Au}-\mathrm{S}$ bond being relatively strong and easy to assemble the $\mathrm{MoS}_{x}$. Assembling $\mathrm{MoS}_{x}$ monolayers on Au should increase the rate of interfacial charge transfer because the increased number of terminal S-atoms on $\mathrm{MoS}_{x}$ precursor derivatives act as active sites for proton reduction [34,35]. Here, we self-assembled the monolayers of $\mathrm{MoS}_{x}$ on to Au from different $\mathrm{MoS}_{x}$ precursor derivatives using immersion, spin-coating, drop-casting and air-drying techniques in an attempt to explore the role of monolayer $\operatorname{MoS}_{x}$ through CV and RRDE measurements and Tafel slope calculations.

\section{Results and Discussion}

Prior to studying their monolayer performances for proton reduction reaction, we previously demonstrated the proton reduction characteristics of thin films resulting from $\left[\mathrm{Mo}_{3} \mathrm{~S}_{7}\left(\mathrm{~S}_{2} \mathrm{CNMe}_{2}\right)_{3}\right] \mathrm{I}$ precursor and a few other precursor derivatives such as $\mathrm{Mo}_{3} \mathrm{~S}_{7}\left(\mathrm{~S}_{2} \mathrm{CNEt}_{2}\right)_{3} \mathrm{I}, \mathrm{Mo}_{3} \mathrm{~S}_{4}\left(\mathrm{~S}_{2} \mathrm{CNEt}_{2}\right)_{4}$, $\left(\mathrm{NH}_{4}\right)_{2}\left[\mathrm{Mo}_{3} \mathrm{~S}_{13}\right]$, and $\left(\mathrm{NBu}_{4}\right)_{2}\left[\mathrm{Mo}_{3} \mathrm{~S}_{13}\right]$. These precursors were spin-coated onto the conducting FTO glass substrates using organic solvents such as THF, DMF, or $\mathrm{CH}_{2} \mathrm{Cl}_{2}$ to obtain catalytic films on FTO. Owing to their limited adherence and stability on FTO, the spin-coated films were annealed at $450{ }^{\circ} \mathrm{C}$ for $1 \mathrm{~h}$ in a $\mathrm{N}_{2}$ environment to obtain crystalline $\mathrm{MoS}_{2}$. The proton reduction HER curves for all the derivatives are shown in Figure 2.

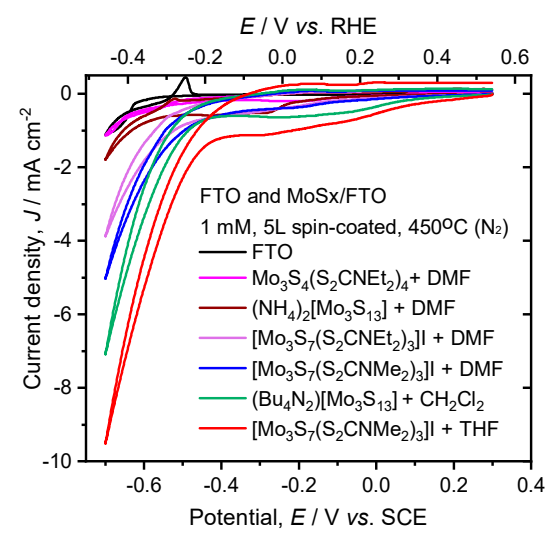

Figure 2. Polarization curves of $\mathrm{MoS}_{2} / \mathrm{FTO}$ electrodes fabricated at $450{ }^{\circ} \mathrm{C}$ in a nitrogen environment. Scan rate: $50 \mathrm{mV} \mathrm{s}^{-1}$; electrolyte: $0.5 \mathrm{M} \mathrm{H}_{2} \mathrm{SO}_{4}$. Reproduced with permission from [24], published by Royal Society of Chemistry, 2018. 
The $\mathrm{MoS}_{2}$ film obtained from $\left[\mathrm{Mo}_{3} \mathrm{~S}_{7}\left(\mathrm{~S}_{2} \mathrm{CNMe}\right)_{3}\right] \mathrm{I}$ in THF exhibited the most promising HER activity. All other films obtained by the post-annealing treatment showed more or less enhanced HER activities than the bare FTO substrate. The major issues with this thin film study are that intrinsic molecular catalytic activities are missing. Therefore, there is a need to prepare self-assembled monolayers (Figure 3) of these molecular precursors on a conductive surface such as gold to learn their proton reduction kinetics.

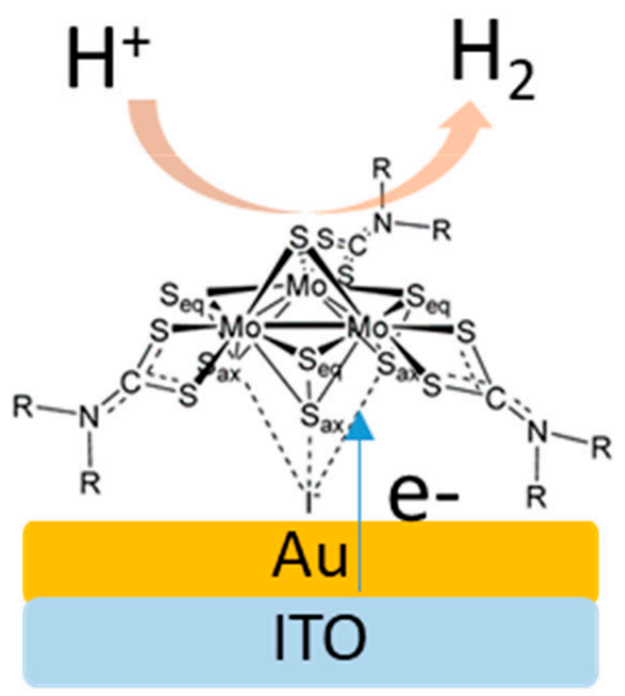

Figure 3. Schematic of $\left[\mathrm{Mo}_{3} \mathrm{~S}_{7}\left(\mathrm{~S}_{2} \mathrm{CNMe}_{2}\right)_{3}\right]^{+}$monolayer-coated Au electrode surface for the catalytic proton reduction reaction.

The benefits of using a monolayer configuration instead of thin films of the Mo-S molecular clusters include: (1) short charge transfer distance for catalyzing proton reduction; (2) intrinsic catalytic characteristics are more likely to be retained than the results shown in Figure 2; and (3) there is no mass transfer effect of molecular catalysts for proton reduction reaction in such heterogeneous system in comparison to that of a homogenous molecular catalysis system for proton reduction.

An XPS study was performed on the $1 \times 1 \mathrm{~cm}^{2}$ ITO coated with Au and the most stable $\mathrm{MoS}_{x}$ precursor, $\left[\mathrm{Mo}_{3} \mathrm{~S}_{7}\left(\mathrm{~S}_{2} \mathrm{CNEt}_{2}\right)_{3}\right] \mathrm{I}$ in DMF, to determine the chemical composition of the Mo-S layer. Figure $4 \mathrm{~A}$ shows the survey spectrum of $\left[\mathrm{Mo}_{3} \mathrm{~S}_{7}\left(\mathrm{~S}_{2} \mathrm{CNEt}_{2}\right)_{3}\right] \mathrm{I}$ precursor assembled on Au-coated ITO surface. The quantitative analysis of the survey spectrum (inset of Figure 4A) revealed the presence of Mo at $30.51 \%$ and sulfur at $69.49 \%$. The actual sulfur-to-molybdenum ratio (S:Mo) obtained from XPS study is ca. 2.278 (69.49:30.51), indicating the formation of sulfur-rich $\operatorname{MoS}_{x}$ monolayer complex on the Au surface. Figure $4 \mathrm{~A}$ also indicates the presence of nitrogen, carbon, and iodine, all of which are present in the precursor derivative. Figure 4B depicts the deconvoluted high-resolution XPS spectra of Mo 3d, S 2p, and C 1s lines. The two peaks at $229.5 \mathrm{eV}$ and $232.7 \mathrm{eV}$ can be attributed to the doublet Mo $3 d_{5 / 2}$ and Mo $3 d_{3 / 2}$, respectively, while the broad peak at $226.9 \mathrm{eV}$ can be identified as $S 2 p$ [31]. The peaks located at 163.7 and $162.5 \mathrm{eV}$ can be ascribed to the $S 2 \mathrm{p}_{1 / 2}$ and $S 2 \mathrm{p}_{3 / 2}$ peaks, respectively. These results are consistent with other reported results for non-stoichiometric $\mathrm{MoS}_{2}$, indicating that the other elements present are impurities rather than the precursor staying intact and being entirely deposited onto the Au surface [36]. For XPS measurement, the substrate was annealed with nitrogen in an attempt to determine whether the entire precursor remained intact and was deposited onto the $\mathrm{Au}$ surface or if the nitrogen and iodine are impurities. The source of the Ag impurity is unknown but suspected to arise from an impurity in the potassium aurocyanide used to deposit the thin film of $\mathrm{Au}$ on to ITO. 

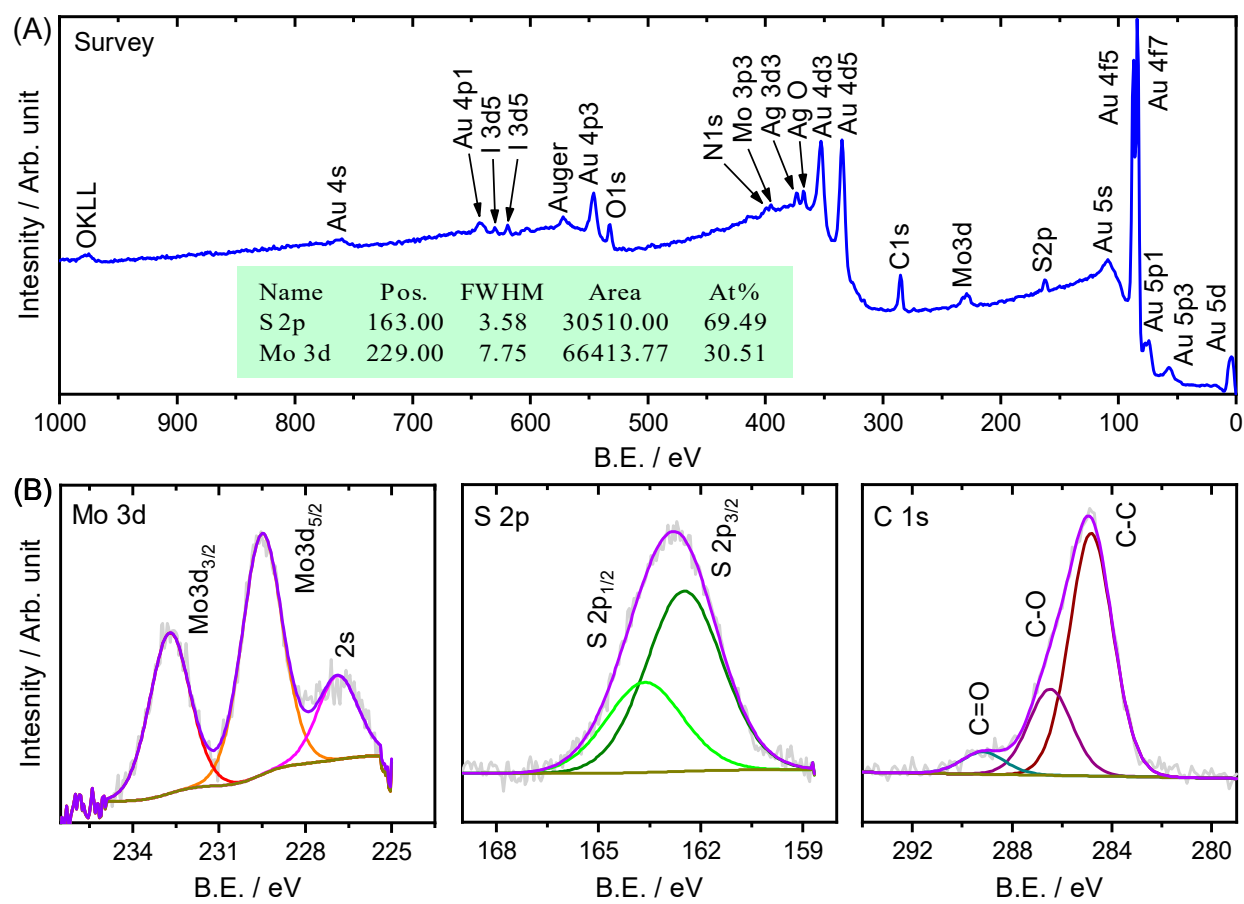

Figure 4. (A) Survey XPS spectrum for $\left[\mathrm{Mo}_{3} \mathrm{~S}_{7}\left(\mathrm{~S}_{2} \mathrm{CNEt}_{2}\right)_{3}\right] \mathrm{I}$ in DMF coated on Au/ITO; Inset shows the elemental compositions for $\mathrm{S}$ and Mo with their respective binding energy (B.E.) positions, full width at half maximum (FWHM) values, areas, and the atomic percentages (at \%); and (B) high resolution deconvoluted XPS spectra of Mo 3d, S 2p and (C) 1s lines for $\left[\mathrm{Mo}_{3} \mathrm{~S}_{7}\left(\mathrm{~S}_{2} \mathrm{CNEt}_{2}\right)_{3}\right] \mathrm{I}$ in DMF coated on $\mathrm{Au} / \mathrm{ITO}$.

To examine the surface coverage of $\mathrm{MoS}_{\mathrm{x}}$ from $\left[\mathrm{Mo}_{3} \mathrm{~S}_{7}\left(\mathrm{~S}_{2} \mathrm{CNMe}_{2}\right)_{3}\right] \mathrm{I}$ in THF, the precursor was deposited onto the Au-disc electrode and run in a solution of $0.1 \mathrm{mM} \mathrm{K}_{3} \mathrm{Fe}(\mathrm{CN})_{6}$ in $1 \mathrm{M} \mathrm{KNO}_{3}$ at different scan rates. Figure 5 shows the $\mathrm{CVs}$ at different scan rates revealing the reduction of electroactive species (ferricyanide to ferrocyanide) in the $\mathrm{K}_{3} \mathrm{Fe}(\mathrm{CN})_{6}$ electrolyte and subsequent oxidation at the surface of Au-disc electrode, before and after modification with the Mo-S clusters, where the current density increases as the scan rate increases.
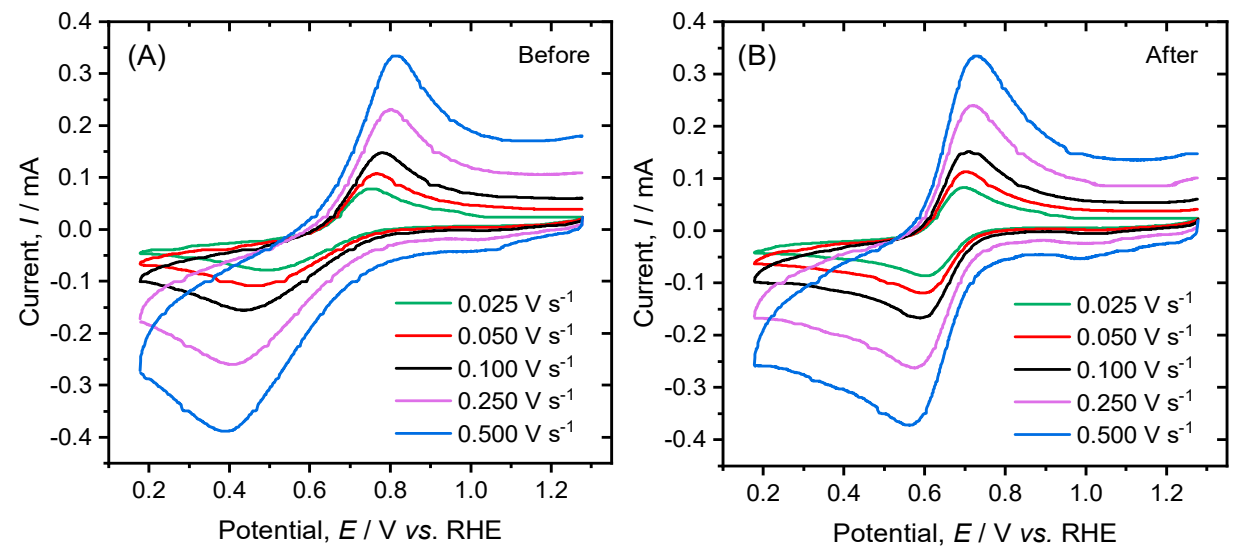

Figure 5. Cyclic voltammetry (CV) curves at different scan rates for surface coverage analysis of $\mathrm{Au}$ disc electrode before (A) and after (B) coating with $\left[\mathrm{Mo}_{3} \mathrm{~S}_{7}\left(\mathrm{~S}_{2} \mathrm{CNMe}_{2}\right)_{3}\right] \mathrm{I}$ in THF. Electrolyte: $1 \mathrm{mM}$ $\mathrm{K}_{3} \mathrm{Fe}(\mathrm{CN})_{6}$ in $0.1 \mathrm{M} \mathrm{KNO}_{3}$.

For $100 \%$ surface coverage, it is expected that the oxidation and reduction peaks would disappear, assuming that $\mathrm{K}_{3} \mathrm{Fe}(\mathrm{CN})_{6}$ does not reduce or oxidize at the surface of the $\mathrm{MoS}_{x}$ monolayer. Thus, since the "before" and "after" CV profiles look relatively similar, inadequate surface coverage is expected. 
To determine the electrochemically active surface area before and after the coating of $\mathrm{MoS}_{x}$, the anodic (or cathodic) peak currents in Figure 5A,B are plotted against the square root of scan rate $(v)$ in Figure 6A,B. The linear dependence of $I_{\mathrm{pa}}$ against $v^{-1 / 2}$ plot means that the electrode reaction is diffusion-controlled. This type of plot is derived from the Randles-Sevcik equation,

$$
I_{\mathrm{p}}=2.69 \times 10^{5} \times A_{\mathrm{ESCA}} \times n^{3 / 2} D^{1 / 2} C v^{1 / 2}
$$

where, $I_{\mathrm{p}}$ is the peak current (anodic or cathodic), $\mathrm{A}_{\mathrm{ESCA}}$ is the electrochemically active surface area, $\mathrm{D}^{1 / 2}$ is the diffusion constant for the electrolyte $\left(D=6.20 \times 10^{-6} \mathrm{~cm}^{2} \mathrm{~s}^{-1}\right.$ for $\left.\mathrm{K}_{3} \mathrm{Fe}(\mathrm{CN})_{6}\right), n$ is the number of electrons transferred $\left(n=1\right.$ for $\left.\left[\mathrm{Fe}(\mathrm{CN})_{6}\right]^{3-/ 4-}\right), v$ is the scan rate, and $\mathrm{C}$ is the concentration of the electrolyte [37]. Using the slope in Figure 6, the Randles-Sevcik equation can be rewritten as follows:

$$
A_{E S C A}=\frac{\operatorname{Slope}\left(I_{p} v s . v^{1 / 2}\right)}{2.69 \times 10^{5} \times n^{3 / 2} \times D^{1 / 2} \times C}
$$
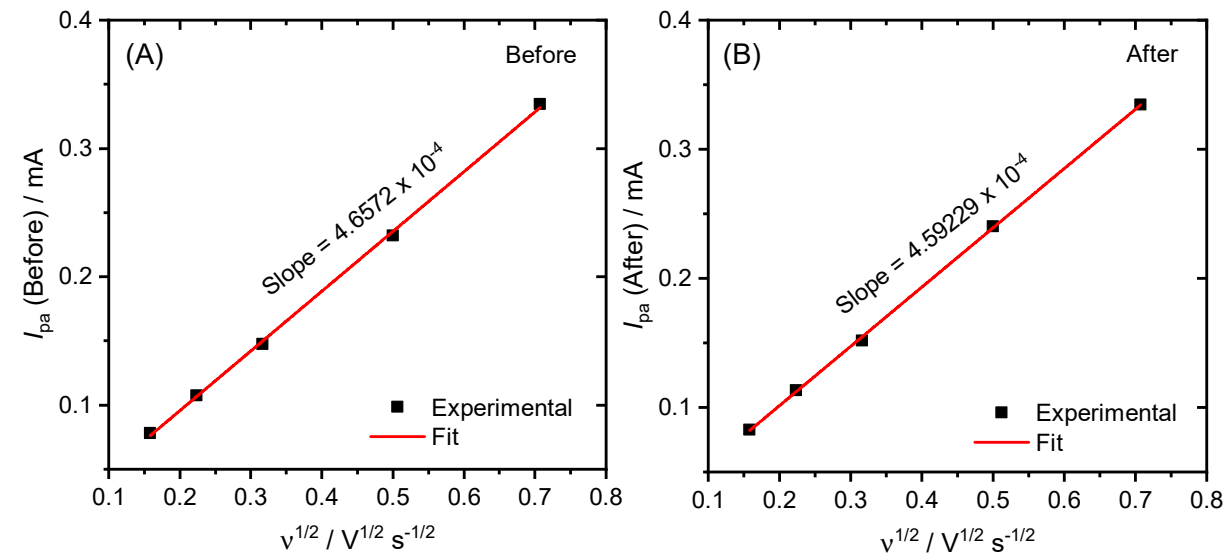

Figure 6. The plots of anodic peak current $\left(I_{\mathrm{pa}}\right)$ versus $v^{-1 / 2}$ (derived from Figure 5) before $(\mathbf{A})$ and after (B) assembling $\operatorname{MoS}_{x}$ monolayer on Au disc.

The change in the electrochemically active surface area $\left(\Delta \mathrm{A}_{\mathrm{ESCA}}\right)$ was calculated to be $3.4 \times 10^{-5} \mathrm{~cm}^{2}$. The percentage of $\mathrm{MoS}_{x}$ coverage can also be calculated from the electrochemically active surface area using the area calculated using both the anodic and cathodic peak currents before and after Mo-S cluster modification, with the percent coverage of ca. $4.7 \%$. This calculation may not be completely accurate, as it assumes that the $\mathrm{K}_{3} \mathrm{Fe}(\mathrm{CN})_{6}$ cannot be reduced or oxidized at the surface of the $\mathrm{MoS}_{x}$ monolayer. However, this is not the case when sufficient overpotential is supplied to overcome the potential barrier of the Mo-S molecular clusters self-assembled onto the Au surface.

Then, the polarization curves of a bare $\mathrm{Au} / \mathrm{ITO}$ electrode and the $\mathrm{MoS}_{x} / \mathrm{Au} / \mathrm{ITO}$ electrodes prepared by dip-coating (overnight immersion) and spin-coating methods were recorded and analyzed. Figure 7 shows the $\mathrm{CV}$ curves of bare $\mathrm{Au} / \mathrm{ITO}$ and $\mathrm{MoS}_{x}$-coated $\mathrm{Au} / \mathrm{ITO}$ electrodes recorded at the scan rate of $50 \mathrm{mV} \mathrm{s}^{-1}$ from $0.5 \mathrm{M} \mathrm{H}_{2} \mathrm{SO}_{4}$. All the $\mathrm{Au} / \mathrm{ITO}$ electrodes underwent oxidation except the one that was immersed overnight in the Mo-S precursor solution. There seems to be little change in the current density for the electrodes. This could be because the electrode is rich in sulfur, as indicated by the XPS quantitative data. Because sulfur vacancy has been reported to influence the catalytic activity, it is fair to conclude that sulfur-rich $\mathrm{MoS}_{x}$ on Au/ITO electrode could be hindering its catalytic ability to be an efficient HER catalyst.

The surface coverage of the $\operatorname{MoS}_{x}$ monolayer was calculated for the immersed substrate for comparison to the data calculated from scan-rate dependent $\mathrm{CV}$ studies using potassium ferricyanide. The immersed $\operatorname{MoS}_{x} / \mathrm{Au} / \mathrm{ITO}$ electrode was used as it is not prone to Au oxidation, indicating that it may have adequate surface coverage. To calculate the surface coverage of $\operatorname{MoS}_{x}$, the oxidation peaks for bare $\mathrm{Au} / \mathrm{ITO}$ and the one dipped overnight were integrated, yielding a surface coverage of $64.4 \%$. 


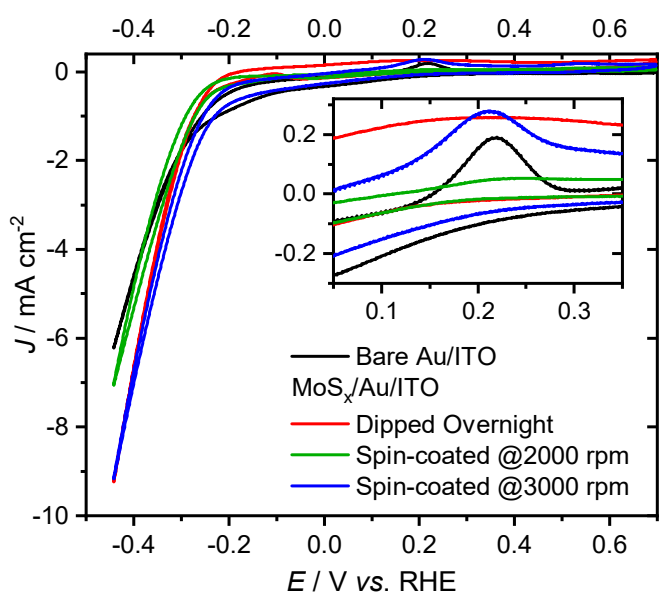

Figure 7. $\mathrm{CV}$ curves recorded for bare and $\mathrm{MoS}_{x}$-coated $\mathrm{Au} / \mathrm{ITO}$ electrodes prepared using $\left[\mathrm{Mo}_{3} \mathrm{~S}_{7}\left(\mathrm{~S}_{2} \mathrm{CNMe}_{2}\right)_{3}\right] \mathrm{I}$ in THF by spin coating and overnight immersion methods. Electrolyte: $0.5 \mathrm{M} \mathrm{H}_{2} \mathrm{SO}_{4}$. The inset of the figure shows the zoom-in features of Au oxidation near $0.2 \mathrm{~V}$ vs. RHE.

To gain insight as to which $\operatorname{MoS}_{x}$ precursor derivative would produce the best HER electrocatalytic activity, CVs were recorded on each of the Au disc electrodes immersed overnight in different $\mathrm{MoS}_{x}$ precursor solutions. Figure $8 \mathrm{~A}$ indicates that $\left(\mathrm{NBu}_{4}\right)_{2}\left[\mathrm{Mo}_{3} \mathrm{~S}_{13}\right]$ in DMF has the highest current density and the $\left[\mathrm{Mo}_{3} \mathrm{~S}_{7}\left(\mathrm{~S}_{2} \mathrm{CNEt}_{2}\right)_{3}\right] \mathrm{I}$ in DMF has the lowest onset potential, which is the minimum potential required for initiation of the catalytic reaction. Repeated CV scans were recorded for each precursor derivative. It is observed that the current density decreased with each scan for each precursor derivative, except for $\left[\mathrm{Mo}_{3} \mathrm{~S}_{7}\left(\mathrm{~S}_{2} \mathrm{CNEt}_{2}\right)_{3}\right] \mathrm{I}$ in DMF. This observation indicates that most of the $\mathrm{MoS}_{\mathrm{x}}$ derivatives were unstable under these conditions.
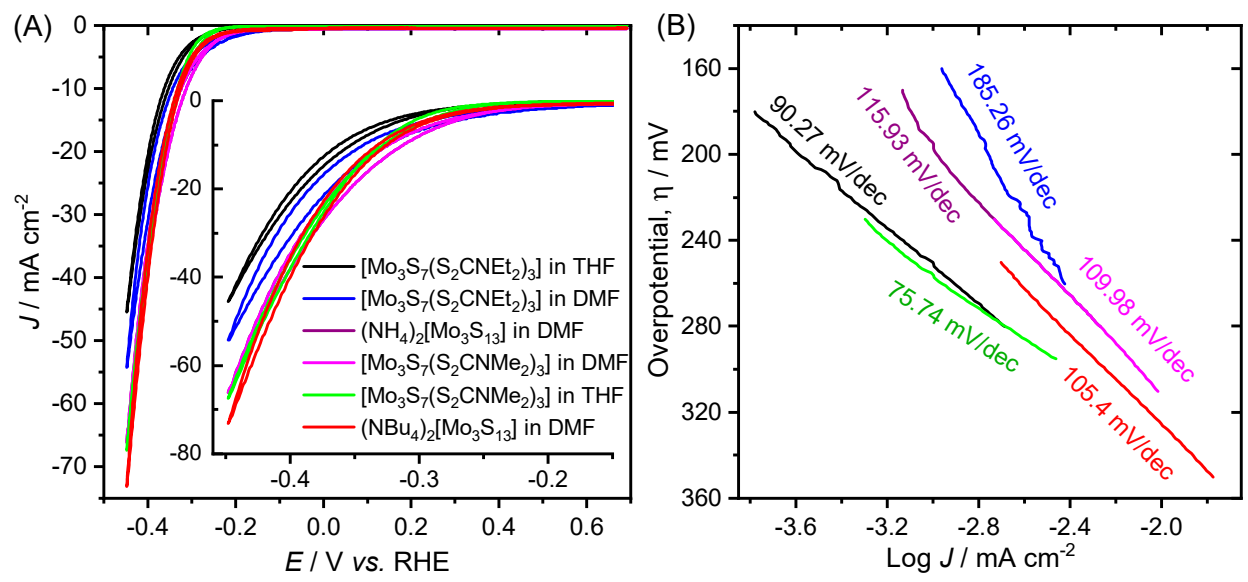

Figure 8. (A) $\mathrm{CV}$ curves of various $\mathrm{MoS}_{2}$ precursor derivatives in $0.5 \mathrm{M} \mathrm{H}_{2} \mathrm{SO}_{4}$; and (B) Tafel plot of $\mathrm{MoS}_{\mathrm{x}}$ derivatives derived from Figure 8A.

To better understand the HER kinetics of the $\mathrm{MoS}_{2}$-modified Au disc electrode, the polarization curves in Figure 8A are plotted in Figure 8B as overpotential $(\eta)$ versus the logarithm of current density $(J)$. This type of plot is known as a Tafel plot. The linear portion near the onset of current is fit to the Tafel equation $\eta=b \log J / J_{0}$, where $J$ is the current density, $J_{0}$ is the exchange current density, and $b$ is the Tafel slope. The Tafel slope is regarded as a measure of catalytic ability. A lower Tafel slope is optimal for Pt-group electrode, which is the best HER catalyst having a Tafel slope of $30 \mathrm{mV} \mathrm{dec}{ }^{-1}$. The $\mathrm{MoS}_{x}$ precursor that was the most stable Au, i.e., $\left[\mathrm{Mo}_{3} \mathrm{~S}_{7}\left(\mathrm{~S}_{2} \mathrm{CNEt}_{2}\right)_{3}\right] \mathrm{I}$ in DMF, has the highest Tafel slope of $185.26 \mathrm{mV} \mathrm{dec}^{-1}$, indicating that it is not a suitable HER catalyst. 
The HER activity of a catalyst in acidic electrolyte generally follows one of two reactions pathways-the Volmer-Tafel or the Volmer-Heyrovsky mechanism-to reduce the protons $\left(\mathrm{H}^{+}\right)$to hydrogen $\left(\mathrm{H}_{2}\right)$. These mechanisms proceed through three reaction steps decided by the Tafel slopes. The rate-limiting steps can be [24]:

(i) Electrochemical hydrogen adsorption, $\mathrm{H}_{3} \mathrm{O}^{+}+\mathrm{e}^{-} \rightarrow \mathrm{H}_{\text {ads }}+\mathrm{H}_{2} \mathrm{O}$ (Tafel slope: $120 \mathrm{mV} \mathrm{dec}{ }^{-1}$ )

(ii) Electrochemical desorption, $\mathrm{H}_{\mathrm{ads}}+\mathrm{H}_{3} \mathrm{O}^{+}+\mathrm{e}^{-} \rightarrow \mathrm{H}_{2}+\mathrm{H}_{2} \mathrm{O}$ (Tafel slope: $40-120 \mathrm{mV} \mathrm{dec}{ }^{-1}$ )

(iii) Chemical desorption, $\mathrm{H}_{\mathrm{ads}}+\mathrm{H}_{\mathrm{ads}} \rightarrow \mathrm{H}_{2}$ (Tafel slope: $30-40 \mathrm{mV} \mathrm{dec}^{-1}$ )

The precursor $\left[\mathrm{Mo}_{3} \mathrm{~S}_{7}\left(\mathrm{~S}_{2} \mathrm{CNMe}\right)_{3}\right] \mathrm{I}$ in THF is thus far the best candidate for HER among all the studied precursors because of its optimal properties in terms of Tafel slope and overpotential. $\operatorname{MoS}_{x}$ resulting from this precursor exhibits a low Tafel slope of $75.74 \mathrm{mV} \mathrm{dec}{ }^{-1}$ and requires the low overpotentials of $331 \mathrm{mV}$ and $410 \mathrm{mV}$ to fetch the HER current densities of 10 and $100 \mathrm{~mA} \mathrm{~cm}^{-2}$, respectively. From the Tafel slope, we can infer that the $\mathrm{MoS}_{x}$ monolayer formed using $\left[\mathrm{Mo}_{3} \mathrm{~S}_{7}\left(\mathrm{~S}_{2} \mathrm{CNMe}_{2}\right)_{3}\right] \mathrm{I}$ in THF follows the Volmer-Tafel mechanism. All these Mo-S clusters are interesting HER catalysts in homogenous solution because of the facile loss of sulfur from the bridging disulfide $\left(\mathrm{S}_{2}{ }^{2-}\right)$ ligands and favorable interaction with protons to facilitate proton reduction upon charge interaction. For example, our study with $\left[\mathrm{Mo}_{3} \mathrm{~S}_{7}\left(\mathrm{~S}_{2} \mathrm{CN}^{i} \mathrm{Bu}_{2}\right)_{3}\right] \mathrm{I}$ suggested superior high turnover frequency of several hundred in several hours during homogeneous photolysis experiments because of its good solubility and favorable HER activities. The difference in the HER activities of these self-assembled derivatives might be associated with the surface coverage and bonding orientation on the Au electrode surface.

To further study the kinetics of this particular precursor, a RRDE study was conducted using glassy carbon (GC) disc electrode. Figure 9 shows the current density responses obtained from $\mathrm{MoS}_{x}$ coated-GC electrode. Protons are reduced on the GC electrode (with or without Au and $\mathrm{MoS}_{x}$ coating) resulting in $\mathrm{H}_{2}$ molecules. The disc current density was higher, and the onset potential was lower for the $\mathrm{MoS}_{x}$-coated GC and $\mathrm{Au} / \mathrm{GC}$ electrodes suggesting that $\left[\mathrm{Mo}_{3} \mathrm{~S}_{7}\left(\mathrm{~S}_{2} \mathrm{CNMe}_{2}\right)_{3}\right] \mathrm{I}$ self-assembled onto the Au surface is a promising HER catalyst. More work is needed to further understand the stability of such $\operatorname{MoS}_{x}$ monolayers and the structural defects through spectroscopy and high-resolution transmission electron microscopy techniques.

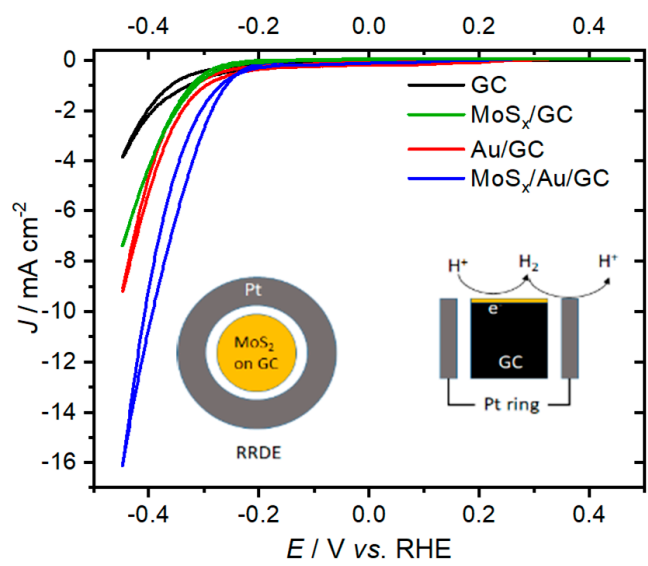

Figure 9. RRDE responses (rotation speed: $4900 \mathrm{rpm}$ ) for bare GC, $\mathrm{Au} / \mathrm{GC}, 0.1 \mathrm{mM} \mathrm{MoS} / \mathrm{GC}$, and $0.1 \mathrm{mMMoS}_{x} / \mathrm{Au} / \mathrm{GC}$ electrodes. The inset shows the schematic diagram of GC-Pt RRDE with deposition of $\mathrm{Au}$ and/or $\mathrm{MoS}_{x} / \mathrm{Au}$ on GC and side view depicting reduction-oxidation reactions on the respective electrodes. Scan rate: $50 \mathrm{mV} \mathrm{s}^{-1}$; electrolyte: $0.5 \mathrm{M} \mathrm{H}_{2} \mathrm{SO}_{4}$ degassed using $\mathrm{N}_{2}$. 


\section{Materials and Methods}

\subsection{Materials}

Potassium ferricyanide $\left(\mathrm{K}_{3} \mathrm{Fe}(\mathrm{CN})_{6}, 99 \%\right.$, Fisher Scientific, San Jose, CA, USA), potassium aurocyanide (KAu $(\mathrm{CN})_{2}$, Orotemp 24, Technic, Cranston, RI, USA), acetone, ethanol, tetrahydrofuran (THF), hydrosulfuric acid $\left(\mathrm{H}_{2} \mathrm{SO}_{4}, 18.4 \mathrm{M}\right)$, nitric acid $\left(\mathrm{KNO}_{3}, 15.6 \mathrm{M}\right)$ and dimethylformamide (DMF) were used as-received without further purification. Commercially available transparent and conducting indium-doped tin oxide (ITO 15-20 $\Omega \mathrm{cm}^{-2}$ )-coated glass substrates were used for thin film deposition of Mo-S precursors. The syntheses of $\left(\mathrm{NBu}_{4}\right)_{2}\left[\mathrm{Mo}_{3} \mathrm{~S}_{13}\right],\left[\mathrm{Mo}_{3} \mathrm{~S}_{7}\left(\mathrm{~S}_{2} \mathrm{CNMe}_{2}\right)_{3}\right] \mathrm{I}$, $\left(\mathrm{NH}_{4}\right)_{2}\left[\mathrm{Mo}_{3} \mathrm{~S}_{13}\right],\left[\mathrm{Mo}_{3} \mathrm{~S}_{7}\left(\mathrm{~S}_{2} \mathrm{CNEt}_{2}\right)_{3}\right] \mathrm{I},\left[\mathrm{Mo}_{3} \mathrm{~S}_{7}\left(\mathrm{~S}_{2} \mathrm{CN}^{i} \mathrm{Bu}_{2}\right)_{3}\right] \mathrm{I}$, and $\left[\mathrm{Mo}_{3} \mathrm{~S}_{7}\left(\mathrm{~S}_{2} \mathrm{CN}^{i} \mathrm{Bu}_{2}\right)_{3}\right] \mathrm{PF}_{6}$ were detailed in our previous published work [24].

\subsection{Preparation and Assembling of Monolayer on Au-Disc Electrode}

The Au-disc electrode (area $=0.0314 \mathrm{~cm}^{2}$ ) was polished using $0.3 \mu \mathrm{m} \mathrm{Al}{ }_{2} \mathrm{O}_{3}$, then $50 \mathrm{~nm} \mathrm{Al}_{2} \mathrm{O}_{3}$, and finally $0.3 \mu \mathrm{m} \mathrm{Al}{ }_{2} \mathrm{O}_{3}$ polish for $5 \mathrm{~min}$ each, moving the electrode in a figure eight motion. The electrode was sonicated in deionized (DI) water for $1 \mathrm{~min}$ and then dried under nitrogen steam between each polish and at the end before immersing the electrode in the solution. The MoS $x$ precursor solutions were all $0.1 \mathrm{mM}$ in $10 \mathrm{~mL}$ of their respective solvents, which were prepared by dilution from a freshly prepared $1 \mathrm{mM}$ stock solution. All solutions were sonicated for $10 \mathrm{~min}$ to ensure the precursor was completely dissolved. The Au-disc electrode was immersed such that it remained suspended in the Mo-S precursor solution overnight.

\subsection{Preparation and Assembling of Monolayer on Au/ITO Electrode}

ITO strips were cut into $1 \times 2 \mathrm{~cm}^{2}$ (or $1.5 \times 2.5 \mathrm{~cm}^{2}$ for spin coating) strips and then subsequently cleaned using detergent, DI water, acetone, and ethyl alcohol and DI water, each for $10 \mathrm{~min}$ in an ultrasonic bath, and finally dried under a nitrogen stream. A thin film of Au was deposited onto the surface of ITO using CV technique in a three-electrode configuration using ITO as the working electrode, graphite as the counter electrode, and silver/silver chloride $(\mathrm{Ag} / \mathrm{AgCl} \mathrm{sat.} \mathrm{KCl})$ as the reference electrode from $\mathrm{KAu}(\mathrm{CN})_{2}$ electrolyte. The $\mathrm{CV}$ was scanned from 0 to -1.5 for 1 cycle at the scan rate of $50 \mathrm{mV} \mathrm{s}^{-1}$. The Au-coated ITO electrodes were immediately washed in DI water and dried with air. Two Au/ITO substrates (size $1 \times 2 \mathrm{~cm}$ ) were immersed overnight in a $0.1 \mathrm{mM}$ solution of $\left[\mathrm{Mo}_{3} \mathrm{~S}_{7}\left(\mathrm{~S}_{2} \mathrm{CNEt}_{2}\right)_{3}\right] \mathrm{I}$ in DMF. One substrate was cut down to $1 \times 1 \mathrm{~cm}^{2}$ for X-ray photoelectron spectroscopy (XPS). The Au/ITO substrate (size $1.5 \times 2.5 \mathrm{~cm}^{2}$ ) was immersed overnight in a $0.1 \mathrm{mM}$ solution of $\left[\mathrm{Mo}_{3} \mathrm{~S}_{7}\left(\mathrm{~S}_{2} \mathrm{CNMe}_{2}\right)_{3}\right] \mathrm{I}$ in THF. Two Au/ITO substrate (size $\left.1.5 \times 2.5 \mathrm{~cm}^{2}\right)$ were cut down to $1.5 \times 1.5 \mathrm{~cm}^{2}$ for spin coating. An $80 \mu \mathrm{L}$ drop of $0.1 \mathrm{mM}$ solution of $\left[\mathrm{Mo}_{3} \mathrm{~S}_{7}\left(\mathrm{~S}_{2} \mathrm{CNMe}_{2}\right)_{3}\right] \mathrm{I}$ in THF was dropped onto the Au/ITO substrate. One was prepared at $2000 \mathrm{rpm}$, and the other was prepared at $3000 \mathrm{rpm}$.

\subsection{RRDE Study}

The RRDE voltammograms were recorded on an RRDE with GC-Pt configuration (ALS Co., Ltd., Tokyo, Japan) having two working electrodes such as glassy carbon (GC) disc (area $=0.5 \mathrm{~cm}^{2}$ ) and $\mathrm{Pt}$ ring electrode (area $=0.75 \mathrm{~cm}^{2}$ ). The RRDE was sonicated for $1 \mathrm{~min}$ in ethanol followed by sonication in DI water for $1 \mathrm{~min}$ and dried under a nitrogen stream. All measurements were performed in $0.5 \mathrm{M}$ $\mathrm{H}_{2} \mathrm{SO}_{4}$ electrolyte at room temperature at the scan rate of $50 \mathrm{mV} \mathrm{s}^{-1}$ using a three-electrode system consisting of the RRDE as the working electrode, silver/silver chloride (Ag/AgCl with sat. $\mathrm{KCl})$ as the reference electrode and a platinum coil as the counter electrode. The rotational speed was varied from 0 to $6400 \mathrm{rpm}$ by squares, and any bubbles on the surface of the working electrode were removed between each measurement. A layer of $\mathrm{Au}$ was deposited onto the surface of GC using the same method as depositing Au onto ITO. A layer of $\mathrm{MoS}_{x}$ was deposited onto the surface of GC (or Au/GC) by drop-casting and air drying a $5 \mu \mathrm{L}$ drop of $0.1 \mathrm{mM}\left[\mathrm{Mo}_{3} \mathrm{~S}_{7}\left(\mathrm{~S}_{2} \mathrm{CNMe}_{2}\right)_{3}\right] \mathrm{I}$ in THF. 


\subsection{Proton Reduction Measurement}

All polarization curves were performed using the following instruments unless otherwise indicated: an electrochemical workstation (CHI 760c, CH Instruments, Austin, TX, USA) and a three-electrode system with graphite or platinum coil as the counter electrode, silver/silver chloride $(\mathrm{Ag} / \mathrm{AgCl}$ sat. $\mathrm{KCl})$ as the reference electrode, and Au-disc electrode as the working electrode. The graphite was washed with DI water and dried with air, and the $\mathrm{Ag} / \mathrm{AgCl}$ electrode was washed with DI water before recording the $\mathrm{CV}$. The electrolyte used for the proton reduction measurements was $0.5 \mathrm{M} \mathrm{H}_{2} \mathrm{SO}_{4}$. The $\mathrm{CV}$ curves were scanned from open circuit potential (OCP) to $-0.7 \mathrm{~V}$ vs. $\mathrm{Ag} / \mathrm{AgCl}$ for 1 cycle at the scan rate of $100 \mathrm{mV} \mathrm{s}^{-1}$. The $\mathrm{MoS}_{\mathrm{x}} / \mathrm{Au} / \mathrm{ITO}$ electrodes prepared by overnight immersion and spin-coating methods using $\left[\mathrm{Mo}_{3} \mathrm{~S}_{7}\left(\mathrm{~S}_{2} \mathrm{CNMe}_{2}\right)_{3}\right] \mathrm{I}$ in THF were assembled in a three-arm electrochemical reactor with an electrolyte exposure area of $0.1807 \mathrm{~cm}^{2}$. All the potential measurements were taken against the $\mathrm{Ag} / \mathrm{AgCl}$ reference electrode and are reported versus the reversible hydrogen electrode (RHE) using the Nernst Equation below:

$$
E_{\mathrm{RHE}}=E_{\text {Reference }}+0.059 \times \mathrm{pH}+E_{\text {Reference }}^{\circ}
$$

where $E_{\mathrm{RHE}}$ is the converted potential versus RHE, $E_{\text {Reference }}$ is the potential measured versus the reference electrode $(\mathrm{Ag} / \mathrm{AgCl}$ sat. $\mathrm{KCl})$, and $E^{\circ}$ Reference is the standard potential of the reference electrode $\left(0.1916 \mathrm{~V}\right.$ for $\mathrm{Ag} / \mathrm{AgCl}$ at $\left.25^{\circ} \mathrm{C}\right)$. The $\mathrm{CVs}$ of the $\mathrm{Au}$-disc electrodes, both bare and coated with $\left[\mathrm{Mo}_{3} \mathrm{~S}_{7}\left(\mathrm{~S}_{2} \mathrm{CNMe}_{2}\right)_{3}\right] \mathrm{I}$ in THF through immersion for surface coverage calculations were recorded in $1 \mathrm{mM} \mathrm{K}_{3} \mathrm{Fe}(\mathrm{CN})_{6}$ in $0.1 \mathrm{M} \mathrm{KNO}_{3}$ at different scan rates such as $0.025,0.05,0.1,0.25$, and $0.5 \mathrm{~V} \mathrm{~s}^{-1}$.

\section{Conclusions}

We successfully assembled the monolayer of $\mathrm{MoS}_{x}$ precursor clusters such as $\left(\mathrm{NBu}_{4}\right)_{2}\left[\mathrm{Mo}_{3} \mathrm{~S}_{13}\right]$, $\left[\mathrm{Mo}_{3} \mathrm{~S}_{7}\left(\mathrm{~S}_{2} \mathrm{CNMe}_{2}\right)_{3}\right] \mathrm{I},\left(\mathrm{NH}_{4}\right)_{2}\left[\mathrm{Mo}_{3} \mathrm{~S}_{13}\right],\left[\mathrm{Mo}_{3} \mathrm{~S}_{7}\left(\mathrm{~S}_{2} \mathrm{CNEt}_{2}\right)_{3}\right] \mathrm{I},\left[\mathrm{Mo}_{3} \mathrm{~S}_{7}\left(\mathrm{~S}_{2} \mathrm{CN}^{i} \mathrm{Bu}_{2}\right)_{3}\right] \mathrm{I}$, and $\left[\mathrm{Mo}_{3} \mathrm{~S}_{7}\left(\mathrm{~S}_{2} \mathrm{CN}^{i} \mathrm{Bu}_{2}\right)_{3}\right] \mathrm{PF}_{6}$. XPS study of $\mathrm{MoS}_{x}$ monolayer assembled on Au using $\left[\mathrm{Mo}_{3} \mathrm{~S}_{7}\left(\mathrm{~S}_{2} \mathrm{CNMe}_{2}\right)_{3}\right] \mathrm{I}$ in THF showed sulfur-rich Mo-S clusters with Mo at $30.51 \%$ and sulfur at $69.49 \%$. The catalytic activity of $\operatorname{MoS}_{x}$ monolayer is hindered by sulfur-rich clusters, which could be improved by the creation of sulfur vacancies. By comparing various $\mathrm{MoS}_{x}$ precursors, we were able to identify the most catalytically active precursor to be $\left[\mathrm{Mo}_{3} \mathrm{~S}_{7}\left(\mathrm{~S}_{2} \mathrm{CNMe}_{2}\right)_{3}\right] \mathrm{I}$ in THF, as it has the optimal properties of having a relatively low Tafel slope of $75.74 \mathrm{mV} \mathrm{dec}^{-1}$ and requiring a lower overpotential of $410 \mathrm{mV}$ to reach a high current density of $100 \mathrm{~mA} \mathrm{~cm}^{-2}$ compared to the other studied precursors. The electrochemically active surface area of $\operatorname{MoS}_{x}$ monomer obtained using this particular precursor was calculated using two different ways with drastically different results, those being $4.7 \%$ from the ferricyanide study and $64.4 \%$ from the spin coating study. The reason for these different results could be due to assuming that ferricyanide does do not reduce at the surface of $\mathrm{MoS}_{x}$ monolayer, which may have been inaccurate. Thus, it is assumed that $64.4 \%$ of surface coverage is a more probable result, as is evident by higher catalytic current density.

Author Contributions: J.P.D. and S.P. conceived and supervised the experiments; P.S.S. and S.S. conducted the electrochemistry and material characterization for proton reduction reaction and XPS characterization; P.R.F. synthesized the Mo-S molecular clusters; and P.S.S. and S.S. analyzed the results and wrote the manuscript. P.S.S. and S.S. hold an equal contribution.

Funding: This research was funded by the National Science Foundation (NSF), grant numbers OIA-1539035, and CHE-1508192.

Acknowledgments: We acknowledge the support of National Science Foundation (NSF) under award number OIA-1539035 and CHE-1508192. We also thank Central Analytical Facility of the University of Alabama for the major characterization facility and Tulane University for providing the precursors used in this study. We also thank Michael Buettner, the research facilities manager of the MINT center, for his assistance with all the XPS measurements.

Conflicts of Interest: The authors declare no conflict of interest. 


\section{References}

1. Blankenship, R.E.; Tiede, D.M.; Barber, J.; Brudvig, G.W.; Fleming, G.; Ghirardi, M.; Gunner, M.R.; Junge, W.; Kramer, D.M.; Melis, A.; et al. Comparing Photosynthetic and Photovoltaic Efficiencies and Recognizing the Potential for Improvement. Science 2011, 332, 805-809. [CrossRef]

2. Armaroli, N.; Balzani, V. Solar Electricity and Solar Fuels: Status and Perspectives in the Context of the Energy Transition. Chem. Eur. J. 2016, 22, 32-57. [CrossRef] [PubMed]

3. Chouhan, N.; Liu, R.-S.; Zhang, J. Photochemical Water Splitting: Materials and Applications; CRC Press: Boca Raton, FL, USA, 2017.

4. Sarina, S.; Waclawik, E.R.; Zhu, H. Photocatalysis on Supported Gold and Silver Nanoparticles Under Ultraviolet and Visible Light Irradiation. Green Chem. 2013, 15, 1814-1833. [CrossRef]

5. Yang, L.; Guo, S.; Li, X. Au Nanoparticles@MoS 2 Core-Shell Structures with Moderate $\mathrm{MoS}_{2}$ Coverage for Efficient Photocatalytic Water Splitting. J. Alloys Compd. 2017, 706, 82-88. [CrossRef]

6. Roger, I.; Shipman, M.A.; Symes, M.D. Earth-Abundant Catalysts for Electrochemical and Photoelectrochemical Water Splitting. Nat. Rev. Chem. 2017, 1. [CrossRef]

7. Li, H.; Tsai, C.; Koh, A.L.; Cai, L.; Contryman, A.W.; Fragapane, A.H.; Zhao, J.; Han, H.S.; Manoharan, H.C.; Abild-Pedersen, F.; et al. Activating and optimizing $\mathrm{MoS}_{2}$ basal planes for hydrogen evolution through the formation of strained sulphur vacancies. Nat. Mater. 2015, 15, 48. [CrossRef]

8. Sun, Y.J.; Liu, C.; Grauer, D.C.; Yano, J.K.; Long, J.R.; Yang, P.D.; Chang, C.J. Electrodeposited Cobalt-Sulfide Catalyst for Electrochemical and Photoelectrochemical Hydrogen Generation from Water. J. Am. Chem. Soc. 2013, 135, 17699-17702. [CrossRef]

9. Voiry, D.; Yamaguchi, H.; Li, J.W.; Silva, R.; Alves, D.C.B.; Fujita, T.; Chen, M.W.; Asefa, T.; Shenoy, V.B.; Eda, G.; et al. Enhanced Catalytic Activity in Strained Chemically Exfoliated $\mathrm{WS}_{2}$ Nanosheets for Hydrogen Evolution. Nat. Mater. 2013, 12, 850-855. [CrossRef]

10. Zhou, Q.; Zhao, G.; Rui, K.; Chen, Y.; Xu, X.; Dou, S.X.; Sun, W. Engineering Additional Edge Sites on Molybdenum Dichalcogenides Toward Accelerated Alkaline Hydrogen Evolution Kinetics. Nanoscale 2019, 11, 717-724. [CrossRef]

11. Zhou, H.Q.; Wang, Y.M.; He, R.; Yu, F.; Sun, J.Y.; Wang, F.; Lan, Y.C.; Ren, Z.F.; Chen, S. One-Step Synthesis of Self-Supported Porous $\mathrm{NiSe}_{2} / \mathrm{Ni}$ Hybrid Foam: An Efficient 3d Electrode for Hydrogen Evolution Reaction. Nano Energy 2016, 20, 29-36. [CrossRef]

12. Xu, Y.F.; Gao, M.R.; Zheng, Y.R.; Jiang, J.; Yu, S.H. Nickel/Nickel(II) Oxide Nanoparticles Anchored onto Cobalt(IV) Diselenide Nanobelts for the Electrochemical Production of Hydrogen. Angew. Chem. Int. Ed. 2013, 52, 8546-8550. [CrossRef]

13. Popczun, E.J.; McKone, J.R.; Read, C.G.; Biacchi, A.J.; Wiltrout, A.M.; Lewis, N.S.; Schaak, R.E. Nanostructured Nickel Phosphide as an Electrocatalyst for the Hydrogen Evolution Reaction. J. Am. Chem. Soc. 2013, 135, 9267-9270. [CrossRef] [PubMed]

14. Jiang, P.; Liu, Q.; Liang, Y.H.; Tian, J.Q.; Asiri, A.M.; Sun, X.P. A Cost-Effective 3D Hydrogen Evolution Cathode with High Catalytic Activity: FeP Nanowire Array as the Active Phase. Angew. Chem. Int. Ed. 2014, 53, 12855-12859. [CrossRef] [PubMed]

15. Fan, L.L.; Liu, P.F.; Yan, X.C.; Gu, L.; Yang, Z.Z.; Yang, H.G.; Qiu, S.L.; Yao, X.D. Atomically Isolated Nickel Species Anchored on Graphitized Carbon for Efficient Hydrogen Evolution Electrocatalysis. Nat. Commun. 2016, 7. [CrossRef] [PubMed]

16. Shi, Z.P.; Wang, Y.X.; Lin, H.L.; Zhang, H.B.; Shen, M.K.; Xie, S.H.; Zhang, Y.H.; Gao, Q.S.; Tang, Y. Porous Nanomoc@Graphite Shell Derived from a MOFs-Directed Strategy: An Efficient Electrocatalyst for the Hydrogen Evolution Reaction. J. Mater. Chem. A 2016, 4, 6006-6013. [CrossRef]

17. Jacques, P.-A.; Artero, V.; Pécaut, J.; Fontecave, M. Cobalt and Nickel Diimine-Dioxime Complexes as Molecular Electrocatalysts for Hydrogen Evolution with Low Overvoltages. Proc. Natl. Acad. Sci. USA 2009, 106, 20627-20632. [CrossRef] [PubMed]

18. Luo, G.-G.; Zhang, H.-L.; Tao, Y.-W.; Wu, Q.-Y.; Tian, D.; Zhang, Q. Recent Progress in Ligand-Centered Homogeneous Electrocatalysts for Hydrogen Evolution Reaction. Inorg. Chem. Front. 2019, 6, 343-354. [CrossRef] 
19. Uchida, T.; Mogami, H.; Yamakata, A.; Sasaki, Y.; Osawa, M. Hydrogen Evolution Reaction Catalyzed by Proton-Coupled Redox Cycle of 4,4'-Bipyridine Monolayer Adsorbed on Silver Electrodes. J. Am. Chem. Soc. 2008, 130, 10862-10863. [CrossRef]

20. McAllister, J.; Bandeira, N.A.G.; McGlynn, J.C.; Ganin, A.Y.; Song, Y.-F.; Bo, C.; Miras, H.N. Tuning and Mechanistic Insights of Metal Chalcogenide Molecular Catalysts for the Hydrogen-Evolution Reaction. Nat. Commun. 2019, 10, 370. [CrossRef]

21. Benck, J.D.; Chen, Z.; Kuritzky, L.Y.; Forman, A.J.; Jaramillo, T.F. Amorphous Molybdenum Sulfide Catalysts for Electrochemical Hydrogen Production: Insights into the Origin of their Catalytic Activity. ACS Catal. 2012, 2, 1916-1923. [CrossRef]

22. Vrubel, H.; Hu, X. Growth and Activation of an Amorphous Molybdenum Sulfide Hydrogen Evolving Catalyst. ACS Catal. 2013, 3, 2002-2011. [CrossRef]

23. Kibsgaard, J.; Chen, Z.; Reinecke, B.N.; Jaramillo, T.F. Engineering the Surface Structure of $\mathrm{MoS}_{2}$ to Preferentially Expose Active Edge Sites for Electrocatalysis. Nat. Mater. 2012, 11, 963. [CrossRef] [PubMed]

24. Shinde, P.S.; Fontenot, P.R.; Donahue, J.P.; Waters, J.L.; Kung, P.; McNamara, L.E.; Hammer, N.I.; Gupta, A.; Pan, S. Synthesis of $\mathrm{MoS}_{2}$ from $\left[\mathrm{Mo}_{3} \mathrm{~S}_{7}\left(\mathrm{~S}_{2} \mathrm{CNEt}_{2}\right)_{3}\right] \mathrm{I}$ for Enhancing Photoelectrochemical Performance and Stability of $\mathrm{Cu}_{2} \mathrm{O}$ Photocathode toward Efficient Solar Water Splitting. J. Mater. Chem. A 2018, 6, 9569-9582. [CrossRef]

25. Merki, D.; Fierro, S.; Vrubel, H.; Hu, X.L. Amorphous Molybdenum Sulfide Films as Catalysts for Electrochemical Hydrogen Production in Water. Chem. Sci. 2011, 2, 1262-1267. [CrossRef]

26. Vrubel, H.; Merki, D.; Hu, X. Hydrogen Evolution Catalyzed by $\mathrm{MoS}_{3}$ and $\mathrm{MoS}_{2}$ Particles. Energy Environ. Sci. 2012, 5, 6136-6144. [CrossRef]

27. Lin, L.; Miao, N.; Wen, Y.; Zhang, S.; Ghosez, P.; Sun, Z.; Allwood, D.A. Sulfur-Depleted Monolayered Molybdenum Disulfide Nanocrystals for Superelectrochemical Hydrogen Evolution Reaction. ACS Nano 2016, 10, 8929-8937. [CrossRef] [PubMed]

28. Xie, J.F.; Zhang, H.; Li, S.; Wang, R.X.; Sun, X.; Zhou, M.; Zhou, J.F.; Lou, X.W.; Xie, Y. Defect-Rich MoS Ultrathin Nanosheets with Additional Active Edge Sites for Enhanced Electrocatalytic Hydrogen Evolution. Adv. Mater. 2013, 25, 5807-5813. [CrossRef] [PubMed]

29. Merki, D.; Vrubel, H.; Rovelli, L.; Fierro, S.; Hu, X. Fe, Co, and Ni Ions Promote the Catalytic Activity of Amorphous Molybdenum Sulfide Films for Hydrogen Evolution. Chem. Sci. 2012, 3, 2515-2525. [CrossRef]

30. Roger, I.; Moca, R.; Miras, H.N.; Crawford, K.G.; Moran, D.A.J.; Ganin, A.Y.; Symes, M.D. The Direct Hydrothermal Deposition of Cobalt-Doped $\mathrm{MoS}_{2}$ onto Fluorine-Doped $\mathrm{SnO}_{2}$ Substrates for Catalysis of the Electrochemical Hydrogen Evolution Reaction. J. Mater. Chem. A 2017, 5, 1472-1480. [CrossRef]

31. Gao, D.; Si, M.; Li, J.; Zhang, J.; Zhang, Z.; Yang, Z.; Xue, D. Ferromagnetism in Freestanding MoS $_{2}$ Nanosheets. Nanoscale Res. Lett. 2013, 8, 129. [CrossRef]

32. Li, G.; Zhang, D.; Qiao, Q.; Yu, Y.; Peterson, D.; Zafar, A.; Kumar, R.; Curtarolo, S.; Hunte, F.; Shannon, S.; et al. All the Catalytic Active Sites of $\mathrm{MoS}_{2}$ for Hydrogen Evolution. J. Am. Chem. Soc. 2016, 138, 16632-16638. [CrossRef] [PubMed]

33. Gan, X.; Zhao, H.; Quan, X. Two-Dimensional $\mathrm{MoS}_{2}$ : A Promising Building Block for Biosensors. Biosens. Bioelectron. 2017, 89, 56-71. [CrossRef] [PubMed]

34. Chatterjee, S.; Sengupta, K.; Bandyopadhyay, S.; Dey, A. Ammonium Tetrathiomolybdate as a Novel Electrode Material for Convenient Tuning of the Kinetics of Electrochemical $\mathrm{O}_{2}$ Reduction by using Iron-Porphyrin Catalysts. J. Mater. Chem. A 2016, 4, 6819-6823. [CrossRef]

35. Zheng, D.; Zhang, G.; Hou, Y.; Wang, X. Layering $\mathrm{MoS}_{2}$ on Soft Hollow g- $\mathrm{C}_{3} \mathrm{~N}_{4}$ Nanostructures for Photocatalytic Hydrogen Evolution. Appl. Catal. A 2016, 521, 2-8. [CrossRef]

36. Eda, G.; Yamaguchi, H.; Voiry, D.; Fujita, T.; Chen, M.; Chhowalla, M. Photoluminescence from Chemically Exfoliated $\mathrm{MoS}_{2}$. Nano Lett. 2011, 11, 5111-5116. [CrossRef] [PubMed]

37. Hamzah, I.H.; Manaf, A.A.; Sidek, O. A Study on Characteristic and Reliability of Fabricated Microfluidic Three Electrodes Sensor Based on Randle-Sevcik Equation. In Proceedings of the 2010 IEEE Asia Pacific Conference on Circuits and Systems, Kuala Lumpur, Malaysia, 6-9 December 2010; pp. 816-819.

(C) 2019 by the authors. Licensee MDPI, Basel, Switzerland. This article is an open access article distributed under the terms and conditions of the Creative Commons Attribution (CC BY) license (http://creativecommons.org/licenses/by/4.0/). 